\title{
Postural Sway and Effect of Levodopa in Early Parkinson's Disease
}

\author{
Anne Beuter, Roberto Hernández, Robert Rigal, Julien Modolo, \\ Pierre J. Blanchet
}

\begin{abstract}
Objective: To characterize postural stability control and levodopa responsiveness in early Parkinson's disease (PD). Methods: Postural sway was studied during quiet stance in ten patients within six years of $\mathrm{PD}$ onset, both before $(\mathrm{OFF})$ and after $(\mathrm{ON})$ regular oral levodopa dosing. Postural sway was recorded using a force platform during $30 \mathrm{sec}$ with eyes open, and six dependent variables were examined. Results: Mild baseline subclinical changes in postural sway were recorded in our patients. Clear benefit was observed in five out of six characteristics (mean sway, transversal sway, sagittal sway, sway intensity, and sway area) in the ON condition. Conclusion: Postural control mechanisms are affected early in PD and modulated by dopamine.

RÉSUMÉ: Objectif: Caractériser le contrôle postural et sa réponse à la L-DOPA dans la maladie de Parkinson (MP) à un stade peu évolué. Méthodologie: L'activité posturo-cinétique a été étudiée à l'orthostation au repos chez 10 patients souffrant de la MP depuis 1-6 ans, avant (état basal ou « OFF ») puis après (état « ON ») l'administration orale de leur dose régulière de L-DOPA. Cette activité a été enregistrée pendant $30 \mathrm{sec}$ les yeux ouverts en utilisant une plateforme de force et 6 variables dépendantes ont été étudiées. Résultats: De légers changements infracliniques de l'activité posturo-cinétique ont été enregistrés chez les patients à l'état basal, et un bénéfice net a été observé sur 5 des 6 caractéristiques (oscillation moyenne, oscillation transversale, oscillation sagittale, intensité d'oscillation et aire d'oscillation) en condition « ON ». Conclusion: Les mécanismes de commande posturale sont affectés précocément dans la maladie de Parkinson et sont modulés par la dopamine.
\end{abstract}

Can. J. Neurol. Sci. 2008; 35: 65-68

A possible role in strength regulation to maintain an upright position and adjustment of coherent postural reactions during body displacement has been suggested for the basal ganglia. ${ }^{1}$ Controlling upright posture also requires the constant use of sensory information analyzed by different neural networks, most often unconsciously. ${ }^{2}$ These signals proceed from proprioceptors (vestibular, muscular, and tendinous), and exteroceptors (visual and cutaneous) used for stability. ${ }^{3}$ Patients with advanced Parkinson's disease (PD) show difficulties in keeping a body position, ${ }^{4}$ particularly the body center of mass, within specific spatial and stability limits in order to maintain equilibrium between stabilizing and destabilizing forces, resulting in falls and injuries that become more and more frequent as the disease progresses. ${ }^{2}$ Their balance difficulties are characterized by a loss of postural balance reactions as well as a decrease in anticipatory postural adjustments. ${ }^{5}$ In one study, ${ }^{6}$ lateral oscillations differentiated PD patients from control subjects while anteriorposterior mean values were comparable in both groups, but greater anterior-posterior than lateral oscillations have also been reported. ${ }^{7}$ The participants in the latter two studies had different mean disease duration ( 7 and 16 years, respectively).

Postural stability control is a crucial aspect of motor function at all PD stages but has not been fully characterized early in the disease. Balance impairment is not considered a presenting feature of the illness and does not draw much attention at that time. ${ }^{8}$ Thus, the risk of falls and injuries in recently diagnosed patients, who may still be at work under demanding physical constraints at that period of their illness, may well be underappreciated. Later on, postural instability in PD is generally felt to be levodopa-resistant and the replacement therapy has even been shown to worsen postural sway abnormalities, ${ }^{7}$ possibly because of decreased automatic tonic postural responses during displacements or interference due to dyskinesias. In this study, we evaluated the effects of levodopa

From the Institut de Cognitique (AB, JM), Université Victor Segalen Bordeaux 2, Bordeaux, France; Département de Kinanthropologie (RH, RR), Université du Québec à Montréal, Montréal; Département de Stomatologie (PJB), Faculté de Médecine Dentaire, Université de Montréal, et Unité des Troubles du Mouvement AndréBarbeau, Centre Hospitalier de l’Université de Montréal, Quebec, Canada. Received March 21, 2007. Final Revisions Submitted October 16, 2007. Reprint requests to: Anne Beuter, Institut de Cognitique, Université Victor Segalen Bordeaux 2, 146, rue Léo Saignat, 33060 Bordeaux Cedex, France. 
on postural stability in mild PD patients with slight or no dyskinesias using a sensitive test battery (CATSYS System). This system uses a force platform to evaluate postural stability. Vertical forces are recorded in three points to determine the position of the centre of pressure on the plate. The movement of the centre of pressure along the X-Y axes defined by the force platform is recorded and analyzed to provide all key information obtained from similar platforms, such as the resultant mean sway, sway velocity, sway area, and Fourier analysis of the sway pattern.

\section{MethodS}

All participants provided informed consent prior to the experiment, which was approved by the local institutional ethics review board. Ten right-handed subjects within six years of PD onset, in Hoehn-Yahr stage I-II, on oral levodopa replacement therapy, were recruited for the study. They were first scored along the Unified Parkinson's Disease Rating Scale (UPDRS)section III in the practically defined OFF state, at least 12 hours after the last dose of antiparkinsonian medications, then tested on the platform, and re-examined 60-90 min after dosing with their regular oral dose of levodopa, regardless of the intensity of their subjective response.

Displacement of the centre of pressure $(\mathrm{CoP})$ was recorded using a 4-cm high platform containing three orthogonal straingauge devices (CATSYS System, Danish Product Development Ltd., Snekkersten, Denmark) connected to a computer. ${ }^{9}$ Platform calibration was performed each day before testing. Postural sway was recorded during $30 \mathrm{sec}$ of quiet stance with eyes open and bare feet $(1 \mathrm{~cm}$ apart) in contact with a non-cushioned surface. Six dependent variables were calculated from the raw data (larger values correspond to lower performance): 1- Resultant mean sway $(\mathrm{mm})$ : Simple mean of the distance from the mean $\mathrm{CoP}$ to all recorded positions (recorded at $31 \mathrm{~Hz}$ ) during the test; 2- Resultant transversal sway ( $\mathrm{mm})$ : Simple mean of the recorded $\mathrm{x}$-direction values of the $\mathrm{CoP}$ in a coordinates system; 3- Resultant sagittal sway ( $\mathrm{mm}$ ): Simple mean of the recorded ydirection values of the CoP in a coordinated system; 4- Resultant sway intensity: Root mean square of acceleration, recorded in the $0.1 \mathrm{~Hz}$ to $10.1 \mathrm{~Hz}$ band during the test period; 5- Resultant sway area $\left(\mathrm{mm}^{2}\right)$ : Area of the smallest polygon including the total trajectory of the $\mathrm{CoP}$ in the horizontal sway plate plane; 6Resultant sway velocity $(\mathrm{mm} / \mathrm{s})$ : Average travel velocity of the $\mathrm{CoP}$ in the horizontal sway plate plane calculated by dividing the total length of the CoP trajectory (in $\mathrm{mm}$ ) by the recording period length (in sec).

An analysis of variance (ANOVA) with repeated measures compared each sway parameter before and after medication. A p value $<0.01$ was considered significant.

\section{RESULTS}

The characteristics of the ten subjects (six males) are summarized (Table 1). The mean $( \pm$ SD) age and disease duration were $61.1( \pm 9.3)$ and $3.3( \pm 1.5)$ years, respectively. All but three

Table 1: Patients demographics and disease characteristics

\begin{tabular}{|c|c|c|c|c|c|c|c|c|}
\hline No & Sex & $\begin{array}{l}\text { Age } \\
\text { (yrs) }\end{array}$ & $\begin{array}{c}\text { Parkinson } \\
\text { duration } \\
(y r s)\end{array}$ & $\begin{array}{c}\text { Hoehn- } \\
\text { Yahr stage } \\
\text { 'OFF' }\end{array}$ & $\begin{array}{l}\text { Stability } \\
\text { (UPDRS } \\
\text { item 29) }\end{array}$ & $\begin{array}{l}\text { UPDRS } \\
\text { OFF }\end{array}$ & $\begin{array}{l}\text { UPDRS } \\
\text { ON }\end{array}$ & Treatment \\
\hline 1 & $\mathrm{M}$ & 70 & 1 & II & 1 & 22 & 21 & LD/CD 100/25 QID \\
\hline 2 & M & 53 & 3 & II & 0 & 16 & 13 & LD/BZ 50/12.5 QID \\
\hline 3 & $\mathrm{~F}$ & 57 & 4 & II & 0 & 18 & 7 & $\begin{array}{l}\mathrm{LD} / \mathrm{CD}-\mathrm{CR} 100 / 251.5 \text { tab } \times 5 \text {, } \\
\text { pramipexole } 1 \mathrm{mg} \text { TID }\end{array}$ \\
\hline 4 & M & 60 & 3 & II & 1 & 26 & 12 & $\begin{array}{l}\mathrm{LD} / \mathrm{CD}-\mathrm{CR} 100 / 25 \mathrm{TID} \\
\text { pramipexole } 1 \mathrm{mg} \text { TID }\end{array}$ \\
\hline 5 & M & 65 & 6 & II & 0 & 22 & 15 & $\begin{array}{l}\mathrm{LD} / \mathrm{CD}-\mathrm{CR} 200 / 50 \mathrm{TID} \text {, } \\
\text { amantadine } 100 \mathrm{mg} \text { BID, } \\
\text { ropinirole } 2 \mathrm{mg} \text { TID }\end{array}$ \\
\hline 6 & $\mathrm{~F}$ & 62 & 2 & I & 0 & 13 & 12 & LD/BZ 50/12.5 TID \\
\hline 7 & $\mathrm{~F}$ & 71 & 4 & II & 1 & 32 & 28 & LD/CD-CR 100/25 QID \\
\hline 8 & $\mathrm{~F}$ & 66 & 3 & II & 0 & 15 & 10 & LD/CD 100/25 QID \\
\hline 9 & M & 40 & 2 & I & 0 & 12 & 6 & $\begin{array}{l}\mathrm{LD} / \mathrm{CD}-\mathrm{CR} 200 / 50 \mathrm{TID} \\
\text { pramipexole } 1 \mathrm{mg} \text { TID }\end{array}$ \\
\hline 10 & $\mathrm{M}$ & 67 & 5 & II & 0 & 16 & 6 & $\begin{array}{l}\text { LD/CD-CR } 200 / 50 \mathrm{BID} \text {, } \\
\text { pergolide } 1.5 \mathrm{mg} \text { TID }\end{array}$ \\
\hline
\end{tabular}

LD: levodopa; CD: carbidopa; BZ: benserazide 
Table 2: Mean $( \pm$ SEM) scores for six dependent variables $(\mathbf{n}=\mathbf{1 0})$

\begin{tabular}{lccc}
\hline $\begin{array}{l}\text { Dependent } \\
\text { variables }\end{array}$ & OFF DOPA & ON DOPA & F values \\
Mean sway* & $7.30(2.90)$ & $6.00(2.00)$ & $14.76^{\mathrm{a}}$ \\
Transversal sway* & $4.65(2.10)$ & $3.71(1.47)$ & $13.59^{\mathrm{a}}$ \\
Sagittal sway* & $4.68(1.98)$ & $3.84(1.38)$ & $9.04^{\mathrm{a}}$ \\
Sway intensity* & $7.80(3.40)$ & $6.46(2.55)$ & $10.53^{\mathrm{a}}$ \\
Sway area** & $450.47(411.06)$ & $297.82(220.68)$ & $10.92^{\mathrm{a}}$ \\
Sway velocity*** & $15.07(7.95)$ & $13.64(6.13)$ & 3.08 \\
\hline
\end{tabular}

* in $\mathrm{mm}$; ** in $\mathrm{mm}^{2} ; * * *$ in $\mathrm{mm} / \mathrm{s}$. ${ }^{a} \mathrm{p}<0.01$ (for $\mathrm{F}$ value: 7.08 )

subjects scored 0 on the UPDRS item 29 for postural stability at baseline (OFF state). The means ( \pm SEM) UPDRS-III score in the OFF and ON states were $19( \pm 6)$ and $13( \pm 7)$ points, respectively. Three subjects (no. 3, 7,8) displayed mild drug-induced dyskinesias.

The postural sway results in the OFF state (Table 2) were retrospectively compared to those previously generated in our laboratory with the CATSYS system in a standardization study, involving 150 normal subjects (50\% men) between 20 and 69 years of age. ${ }^{9}$ The control results can be accessed at the following web site: http://www.er.uqam.ca/nobel/r11040/ resultat.htm. Mild differences were observed in all five measures examined both in the present and standardization studies (mean sway, transversal and sagittal sway, sway area and velocity). The values in the OFF state were either slightly above (transversal sway and sway velocity) or slightly below (mean sway, sagittal sway and sway area) one standard deviation compared to control values. These differences affect stance in general and have been reported in more advanced PD patients. ${ }^{10}$ The measures most affected by the disease were transversal sway and sway velocity.

Compared to baseline measures, five of the six sway variables improved on levodopa: mean sway, transversal and sagittal sway, sway intensity and sway area (Table 2). Only sway velocity did not improve significantly but as indicated above, the sway velocity mean value recorded in patients also differs from the mean value recorded in the control group and does not seem as representative as the other measures. ${ }^{9}$ Levodopa induced a substantial improvement on postural sway in eight participants. The impact on sway area (up to $72 \%$ ) was particularly robust (Figure). Two patients (no. 1, 10) showed a noticeable deterioration following levodopa administration, but one of them did not achieve an adequate ON state (no. 1). Except for the sway velocity results, the mean values recorded in the levodopa condition were otherwise comparable to our previous control values. ${ }^{8}$

\section{DiscuSSION}

We have shown that mild subclinical changes in postural sway do exist in early PD. The disease influences three postural control modalities: basic postural tone, internal postural control, as well as postural control when an external perturbation is applied. ${ }^{11}$ Balance problems in subjects with PD are dominated by a loss of balance reactions and a decrease in anticipatory postural adjustments. ${ }^{5}$ As a result, these patients have a delay in movement initiation and execution particularly in unsteady balance conditions. The voluntary dynamic action of postural stability control is reduced ${ }^{12}$ making PD subjects particularly vulnerable to falls at the time of internal or external destabilization.

Our results also indicate that levodopa replacement does help postural stability control in PD patients. The magnitude of the changes observed under medication can hardly be explained by the nonrandomized order of testing (OFF drug then ON), since familiarization and motor learning alone would be expected to produce a much lower degree of improvement. One can speculate that dopamine modulates the treatment of feedback information from the vestibular system and lower limbs proprioceptors. The effect of dopamine depletion (OFF condition) on mean velocity oscillations was evident in another

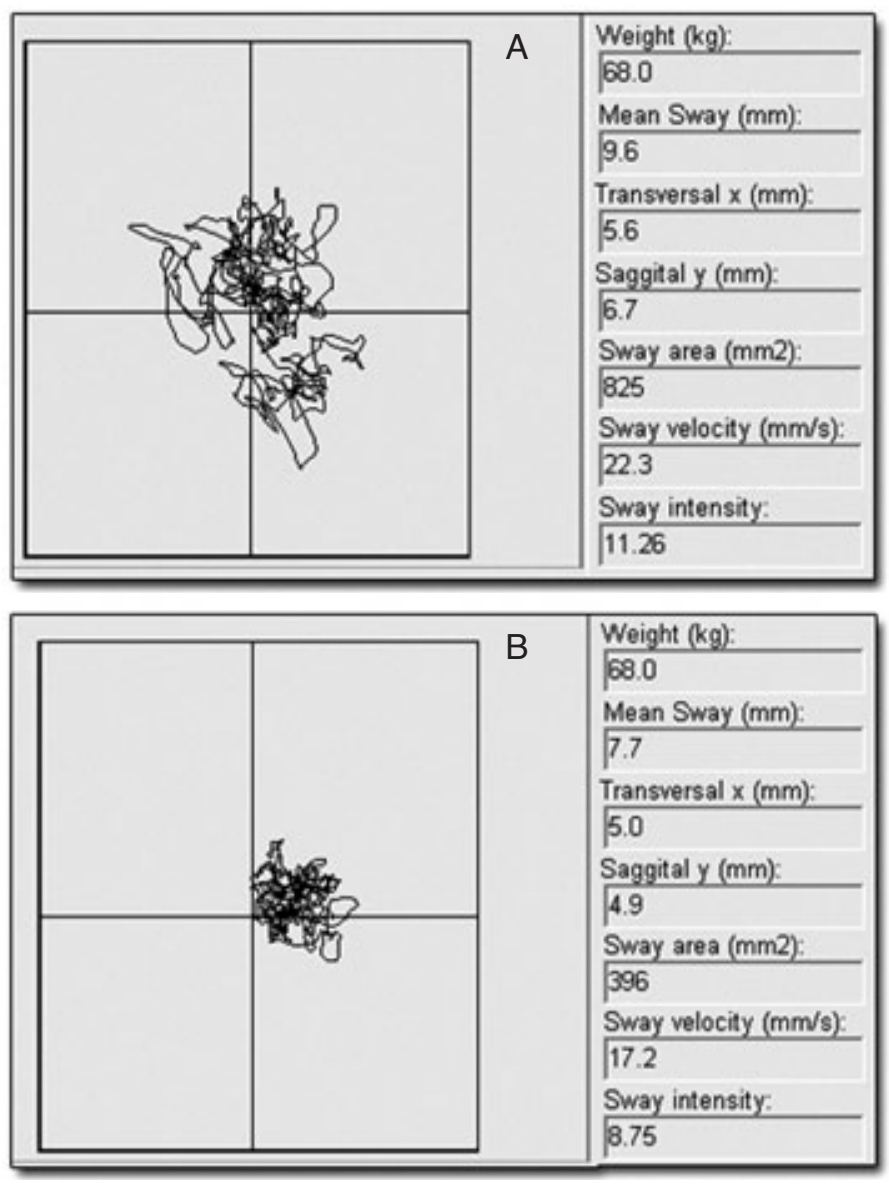

Figure: Example of the sway area of the centre of pressure $(\mathrm{CoP})$ displacement recorded with a CATSYS platform in case \#2: (A) OFF levodopa, (B) ON levodopa. 
study: ${ }^{7}$ in the OFF condition, this speed reached close to 80 $\mathrm{mm} / \mathrm{s}$, compared to $25 \mathrm{~mm} / \mathrm{sec}$ in the $\mathrm{ON}$ condition. That velocity is higher than in the present experiment probably because of differences in disease duration and severity.

The role attributed to levodopa on postural control in PD remains unclear due to inconsistent data. For instance, the area inclusion of the CoP displacements has been shown to be closer to normal in OFF compared to ON condition..$^{1,7}$ In our study, the positive impact of levodopa was clear in eight of ten subjects, confirming previous reports about the benefit of levodopa on the activation of motor reflexes in $\mathrm{PD},{ }^{13-16}$ even in advanced subjects. ${ }^{17-18}$ For instance, the prominent $1 \mathrm{~Hz}$ oscillations documented in patients in the OFF condition diminished significantly in amplitude with levodopa and high-frequency stimulation of the subthalamic nucleus. ${ }^{19}$ These differences were attributed to a change of gain in feedback loops, increased in $\mathrm{ON}$ and decreased in OFF state. Thus, dopaminergic circuits may be involved in postural control and internal stability. On the other hand, force control during external postural reactions could recruit non-dopaminergic circuits, explaining its lack of responsiveness in the $\mathrm{ON}$ condition. The basal ganglia conceivably contribute to postural control through different circuits. ${ }^{11,20}$ Differences in disease duration and severity, as well as in individual medication dose and magnitude of response, may have contributed to the slight performance deterioration detected in two of our subjects. A levodopa test using a standard dose in a greater number of participants would have been advantageous.

In conclusion, this study showed that mild subclinical changes in postural sway exist within six years of PD onset. The risk of falls of early PD patients in household and professional activities should not be overlooked. Oral levodopa dosing diminished postural sway in stance, suggesting that postural control mechanisms in early PD are under dopamine modulation. In advanced PD, degeneration of non-dopaminergic circuits and changes in the response profile to levodopa over time may explain the partial impact of levodopa on postural control.

\section{ACKNOWLEDGMENTS}

The authors thank all participants and Ms. Chantal Beauvais, $\mathrm{RN}$, for her involvement in the study. Supported by a grant from NSERC (AB) and BIOSIM (EC) \#LSHB-CT-2004-005137.

\section{REFERENCES}

1. Horak FB, Frank J, Nutt JG. Effects of dopamine on postural control in parkinsonian subjects: scaling set and tone. J Neurophys. 1996;75(6):2380-96.

2. Romero DH, Stelmach GE. Changes in postural control with aging and Parkinson's disease. IEEE Eng Med Biol Mag. 2003; 22(2):27-31.

3. Bessou M, Severac Cauquil A, Dupui P, Montoya R, Bessou P. Specificity of the monocular crescents of the visual field in postural control. CR Acad Sci III. 1999;322(9):749-57.

4. Kemoun G, Watelain E, Defebvre L, Guieu JD, Destee A. Postural strategies and falls in elderly and in parkinsonism. Ann Readapt Med Phys. 2002;4(9):485-92.

5. Bazalgette D, Zattara M, Bouisset S, Bathien N, Rondot P. Postural adjustments associated with rapid arm movements in Parkinson's disease. In: Proceedings of VIIth International Symposium on Parkinson's Disease. Adv Neurol. 1986;45:371-4.

6. Viitasalo MK, Kampman V, Sotaniemi KA, Leppävuori S, Myllylä VV, Korpelainen JT. Analysis of sway in Parkinson's disease using a new inclinometry-based method. Mov Disord. 2002;17(4):663-9.
7. Rocchi L, Chiari L, Horak FB. Effects of deep brain stimulation and levodopa on postural sway in Parkinson's disease. J Neurol Neurosurg Psychiatry. 2002;73:267-74.

8. Hermanowicz N. Management of Parkinson's disease: strategies, pitfalls and future directions. Postgrad Med. 2001;110(6):15-28.

9. Despres C, Lamoureux D, Beuter A. Standardization of a neuromotor test battery: The CATSYS System. Neurotoxicology. 2000;21(5):725-36.

10. Bartolic A, Pirtosek Z, Rozman J, Ribaric S. Postural stability of Parkinson's disease patients is improved by decreasing rigidity. Eur J Neurol. 2005;12:156-9.

11. Frank JS, Horak FB, Nutt J. Centrally initiated postural adjustments in parkinsonian patients on and off levodopa. J Neurophys. 2000;84:2440-8.

12. Panzer-Decius V, Nashner LM, Beckley DJ, Chase TN. Quantification of dopaminomimetic effects on Parkinsonian symptoms using automatic and voluntary postural response. In: Przuntek H, Kraus PH, Klotz P, Korczyn AD, editors. Instrumental methods and scoring in extrapyramidal disorder. New York: Springer-Verlag; 1996. p. 150-60.

13. Horak FB, Macpherson JM. Postural orientation and equilibrium. In: Rowell L, Shepherd JT, editors. Regulations and integration of multiple systems. (Handbook of physiology, sect. 12, Exercise). New York:Oxford University Press; 1991. p. 255-92.

14. Horak FB, Nutt JG, Nashner LM. Postural inflexibility in parkinsonian subjects. J Neurol Sci. 1992;111:46-58.

15. Horak FB, Shupert C. The role of the vestibular system in postural control. In: Herdman S, editor. Vestibular Rehabilitation. New York: FA Davis; 1994. p. 22-46.

16. Nova IC, Perracini MR, Ferraz HB. Levodopa effect upon functional balance of Parkinson's disease patients. Parkinsonism Rel Disord. 2004;10:411-15.

17. Bejjani B-P, Gervais D, Arnulf I, Papadopoulos S, Demeret S, Bonnet A-M, et al. Axial parkinsonian symptoms can be improved: the role of levodopa and bilateral subthalamic stimulation. J Neurol Neurosurg Psychiatry. 2000;68:595-600.

18. Defebvre LJP, Krystkowiak P, Blatt J-L, Duhamel A, Bourriez J-L, Perina $\mathrm{M}$, et al. Influence of pallidal stimulation and levodopa on gait and preparatory postural adjustments in Parkinson's disease. Mov Disord. 2002;17(1):76-83.

19. Maurer C, Mergner T, Peterka RJ. Abnormal resonance behaviour of the postural control loop in Parkinson's disease. Exp Brain Res. 2004;157(3):369-76.

20. Dimitrova D, Nutt J, Horak FB. Abnormal force patterns for multidirectional postural responses in patients with Parkinson's disease. Exp Brain Res. 2004;156:183-95. 